\title{
Job Satisfaction among Sudanese Community physicians
}

\author{
Abdalla E A Simsaa ${ }^{1}$, Modawy E Modawy ${ }^{1}$, Omer Ibrahim Abdallah ${ }^{1}$, Alashary \\ A Hamdoon ${ }^{1}$. \\ ${ }^{I}$ Department of public health, College of health sciences at Al Leith, Umm Al-Qura University, Kingdom of \\ Saudi Arabia.
}

\begin{abstract}
This is a descriptive cross- sectional, institutional- based study. It aimed to assess the degree of job satisfaction of the Sudanese community physicians. Self- administered questionnaires were sent to all Sudanese community physicians (82) who are present at the time of this study in their locations of work. One-third of the Sudanese community physicians are females, and $90.2 \%$ of all the Sudanese community physicians are married. Only $34.6 \%$ of them were found to be satisfied with their jobs. Neither age nor marital status is significantly associated with job satisfaction. Female Sudanese community physicians are more highly significantly dissatisatisfied by their work as compared to their male counterparts. They are all highly dissatisfied by the availability of the promotion opportunities, as the chances for continuous medical education or doing subspecialties. One of the most dissatisfying factors was found to be the low salaries and incentives, as it is highly significantly associated with job satisfaction. As the result of this wide spread dissatisfaction $71.6 \%$ of the Sudanese community physicians have the tendency to leave their current governmental posts, under the condition that they find new better satisfying posts inside or abroad.
\end{abstract}

Keywords: job satisfaction, community physicians, dissatisatisfaction, ministries of health, Sudan.

\section{Introduction}

Job satisfaction is an important issue nowadays especially in the medical field as it is interrelated with the quality of health care, its continuity, the physician's performance, productivity, commitment, retention and resignation. Moreover, dissatisfaction leads to increased physician's absenteeism, lower productivity, increased turnover, and hence adversely affects the quality and outcome of the health care system. In contrast, a satisfied health workforce is more committed, highly productive and more likely to be creative, innovative, initiative and enthusiastic $(1,2)$.There are many factors that can affect the level of job satisfaction; some of these factors include the payment, opportunities for professional development, opportunities for using skills and abilities, the quality of working conditions, social relations and the job itself $(1,2)$.The long civil war in the South and the recent one in the West had resulted in a worse internal displacement problem. This displacement increases the numbers of vulnerable groups which has a negative impact on the health situation. Sudan also experienced repeated humanitarian emergencies related to drought and flooding exposing much of our population to major infectious and parasitic diseases.Adding to this the recent increasing burden of non-communicable diseases and poverty. This situation can facilitates disease transmission, epidemics occurrence and makes tremendous difficulties on health care delivery beside disease control and surveillance. All these factors had severely affected the health status of this country, its health infrastructure and economy.The Sudan House Hold Health Survey (SHHS), conducted in the year 2006 was the first national survey covering the whole country since more than two decades ago because of the long conflicts in Sudan (3). This survey revealed that the percentage of children who were fully immunized as recommended by WHO and UNICEF (BCG, Polio-3, DPT-3\&Measles) were $41.4 \%$, IMR in the Sudan as a whole was $81 / 1000$ live births and the under 5-MR was 112/1000 live births. Estimates of neonatal, post- neonatal and child mortality rates were respectively 41, 40, and34 per 1000 live births, while MMR was found to be 1107/100,000 live births. This is only part of Sudan's epidemiological profile showing an unacceptable reality calling for urgent interventions. According to the FMOH ten years' strategic plan for H.R.H. (2004-2013) Sudan health care system is in need of 462 community physicians to run this system (4). At the present time there are only 90 of them joining this system, 6 of them were sent abroad for further studies (5for short courses and 1for a long course). As only 90 (28.8\%) out 313 registered community physicians are joining this system (5) it is obvious that these important cadres present a challenge to the official health care system, as the majority of them (71.2\%) are working in places other than governmental facilities.

\section{Materials and Methods}

This is a descriptive cross-sectional, institutional- based study. It includes all Sudanese community physicians who are registered at Sudan Medical Council and currently working in Sudan ministries of health. A Self-administered questionnaire was used to collect the required data. Data was analyzed using the SPSS statistical package. Chi-square test as statistical tool was used for measuring the significance of the study results. 


\section{Results}

Fig (1) is showing that $71.6 \%$ of the community physicians have the tendency to leave their governmental jobs. Fig (2) is showing that only $34.6 \%$ the community physicians were found to be satisfied with their jobs.

Fig (3) is showing the different levels of job satisfaction among the community physicians

There is no significant a statistical relationship between age and job satisfaction Table(1) .

There is no significant a statistical relationship between marital status and job satisfaction Table(2) .

There is a highly significant statistical relationship between gender and job satisfaction Table (3).

There is a significant statistical relationship between having subspecialty and job satisfaction Table(4) .

There is a highly significant statistical relationship between the availability of continuous education and job satisfaction Table(5) .

There is a highly significant statistical relationship between monthly income and job satisfaction Table (6).

Table (1) showing relationships between age and job satisfaction of the, Sudan ministries of health, Sudan

\begin{tabular}{|l|l|l|l|}
\hline \multirow{2}{*}{ AGE GROUPS } & Job satisfaction $(\mathrm{n}=81)$ & \multirow{2}{*}{ TOTAL } \\
\cline { 2 - 4 } & Satisfied & Dissatisfied & \\
\hline \multirow{3}{30-40}{} & 7 & 18 & 25 \\
& $28 \%$ & $72 \%$ & $100 \%$ \\
\hline $\mathbf{4 1 - 5 0}$ & 18 & 23 & 41 \\
& $43.9 \%$ & $56.1 \%$ & $100 \%$ \\
\hline $\mathbf{6 0 - 5 1}$ & 3 & 12 & 15 \\
& $20 \%$ & $80 \%$ & $100 \%$ \\
\hline TOTAL & 28 & 53 & 81 \\
& $34.6 \%$ & $65.4 \%$ & $100 \%$ \\
\hline
\end{tabular}

Chi-square $\quad=3.46$

$\mathrm{P}$ value $\quad=0.1$

Table (2) Relationship between marital status and job satisfaction, Sudan ministries of health, Sudan. $(\mathrm{n}=81)$

\begin{tabular}{|l|l|l|l|}
\hline \multirow{2}{*}{ Marital Status GROUPS } & Job satisfaction & \multirow{2}{*}{ TOTAL } \\
\cline { 2 - 4 } & Satisfied & Dissatisfied & \\
\hline \multirow{2}{*}{ Single } & 24 & 49 & 73 \\
& $32.9 \%$ & $67.1 \%$ & $100 \%$ \\
\hline \multirow{2}{*}{ Divorced } & 3 & 4 & 7 \\
& $42.9 \%$ & $57.1 \%$ & $100 \%$ \\
\hline
\end{tabular}

Chi-square $\quad=2.19$

$\mathrm{P}$ value $\quad=0.33$

Table (3) Relationship between gender and job satisfaction, Sudan ministries of health, Sudan. $(n=81)$

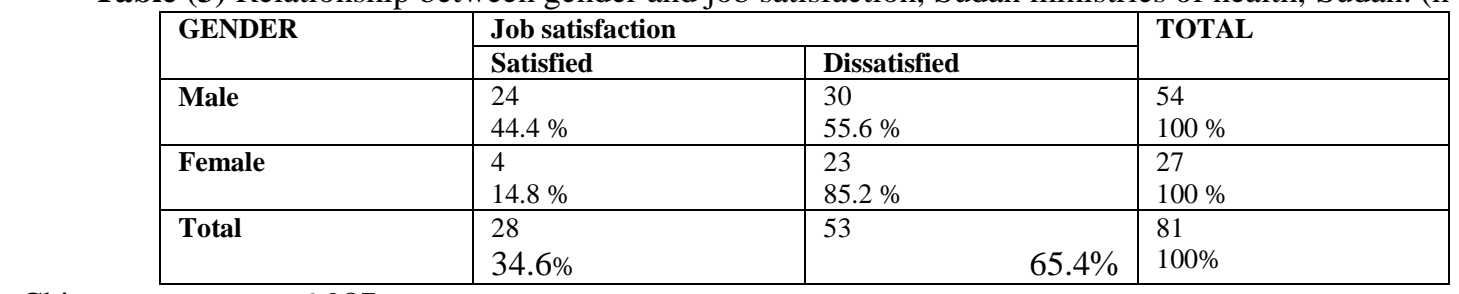

Chi-square $\quad=6.987$

$\mathrm{P}$ value $\quad=0.008$

Table (4) Relationship between having subspecialty and job satisfaction, Sudan ministries of health, Sudan.

\begin{tabular}{|c|c|c|c|}
\hline \multirow[t]{2}{*}{ Having Subspecialty } & \multicolumn{2}{|c|}{ Job satisfaction } & \multirow[t]{2}{*}{ TOTAL } \\
\hline & Satisfied & Dissatisfied & \\
\hline YES & $\begin{array}{l}9 \\
56 \%\end{array}$ & $\begin{array}{l}7 \\
44 \%\end{array}$ & $\begin{array}{l}16 \\
\% 100\end{array}$ \\
\hline NO & $\begin{array}{l}19 \\
29 \%\end{array}$ & $\begin{array}{l}46 \\
71 \%\end{array}$ & $\begin{array}{l}65 \\
\% 100\end{array}$ \\
\hline Total & $\begin{array}{l}28 \\
34.6 \%\end{array}$ & $\begin{array}{l}53 \\
65.4 \%\end{array}$ & $\begin{array}{l}81 \\
100 \%\end{array}$ \\
\hline
\end{tabular}


Table (5) Relationship between the availability of continuous medical education and job satisfaction, Sudan ministries of health, Sudan. $(\mathrm{n}=81)$.

\begin{tabular}{|c|c|c|c|}
\hline \multirow{2}{*}{$\begin{array}{l}\text { Availability } \\
\text { Of continuous } \\
\text { Education }\end{array}$} & \multicolumn{2}{|c|}{ Job satisfaction } & \multirow[t]{2}{*}{ TOTAL } \\
\hline & Satisfied & Dissatisfied & \\
\hline YES & $\begin{array}{l}22 \\
66.7 \%\end{array}$ & $\begin{array}{l}11 \\
33.3 \%\end{array}$ & $\begin{array}{l}33 \\
\% \quad 100\end{array}$ \\
\hline NO & $\begin{array}{l}6 \\
12.5 \%\end{array}$ & $\begin{array}{l}42 \\
87.5 \%\end{array}$ & $\begin{array}{l}48 \\
\% \quad 100\end{array}$ \\
\hline Total & $\begin{array}{l}28 \\
34.6 \%\end{array}$ & $\begin{array}{l}53 \\
65.4 \%\end{array}$ & $\begin{array}{l}81 \\
100 \%\end{array}$ \\
\hline
\end{tabular}

Chi-square $=25.36$

$\mathrm{P}$ value $\quad=0.000$

Table (6) Relationship between monthly income and job satisfaction, Sudan ministries of health, Sudan. (n=81)

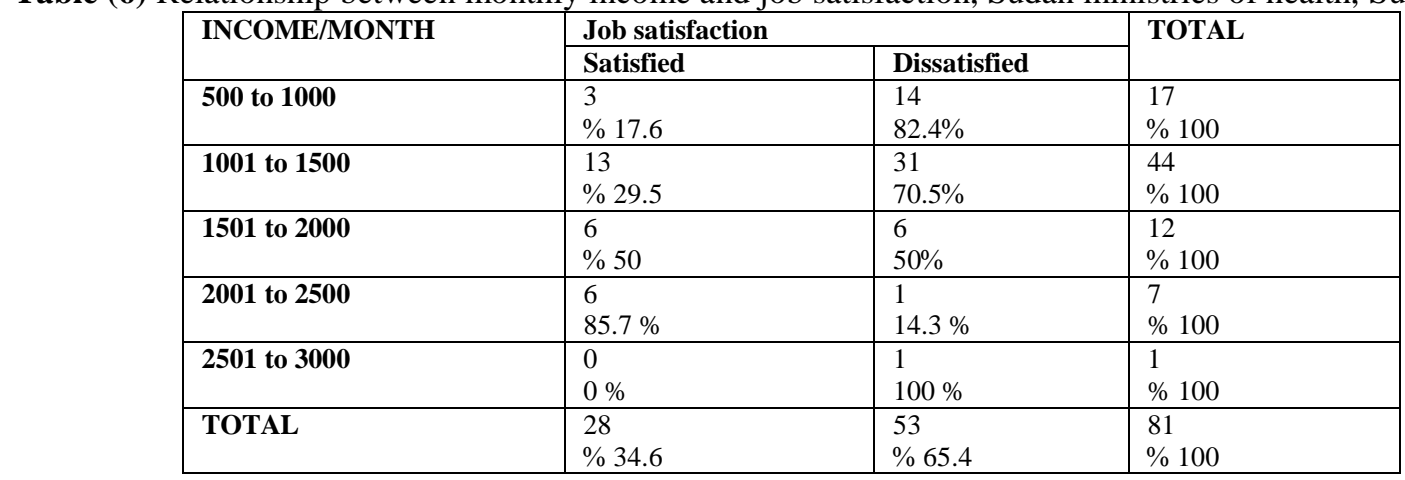

Chi-square

$=12.53$

$P$ value

$$
=0.01
$$

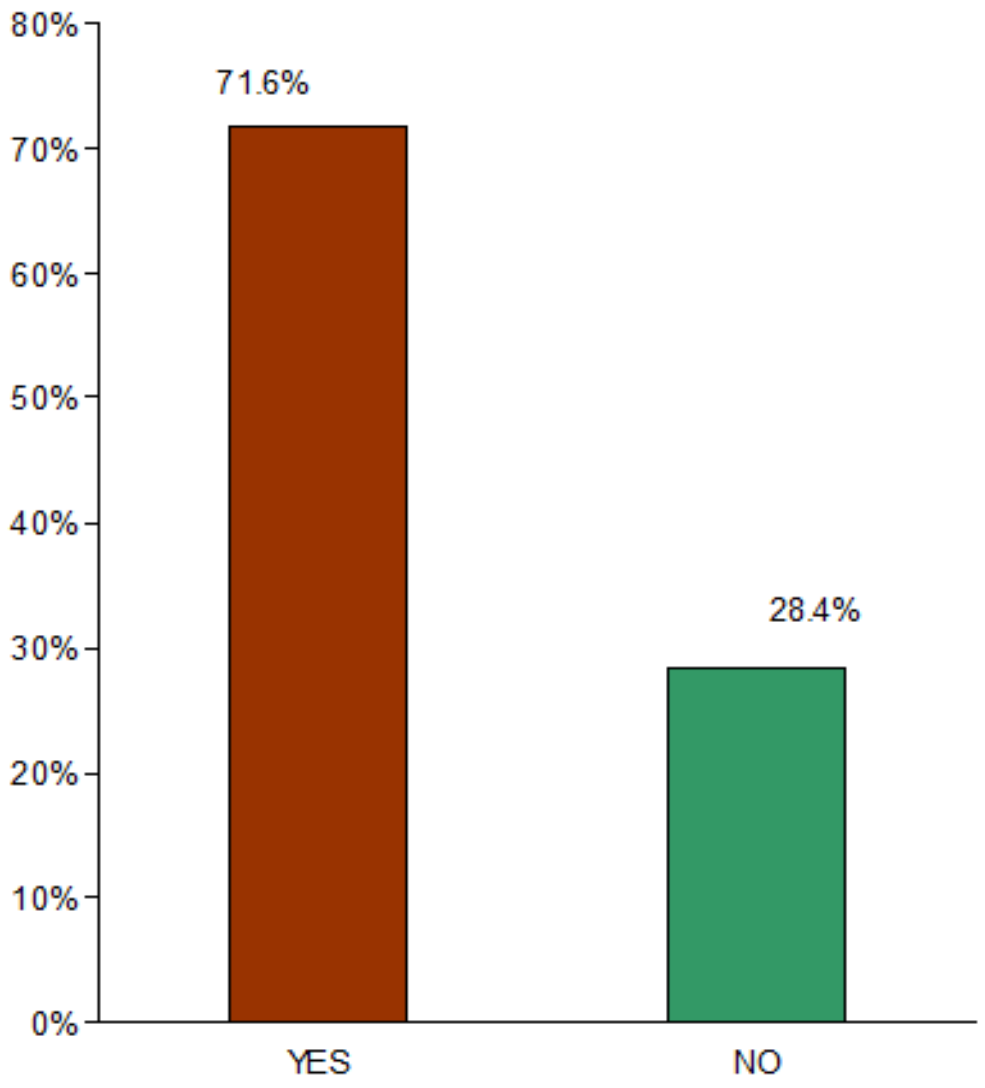

Tendency to leave the job

Fig (1) The percentage of the community physicians who have the tendency to leave their governmental jobs,

Sudan ministries of health, Sudan. $(n=81)$ 


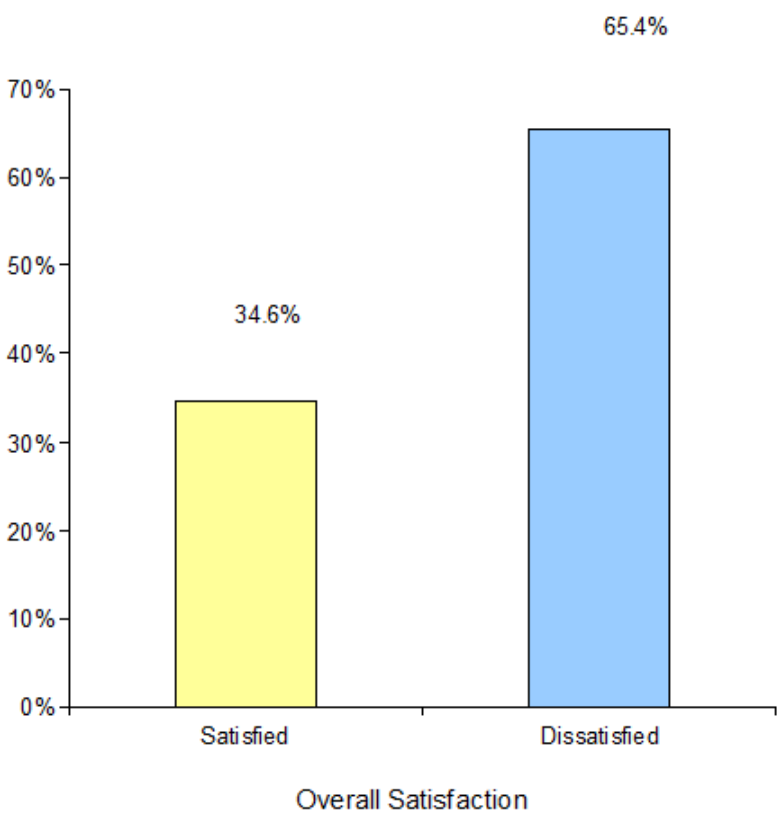

Fig (2) The overall job satisfaction among the community physicians, Sudan ministries of health, Sudan. $(\mathrm{n}=81)$.

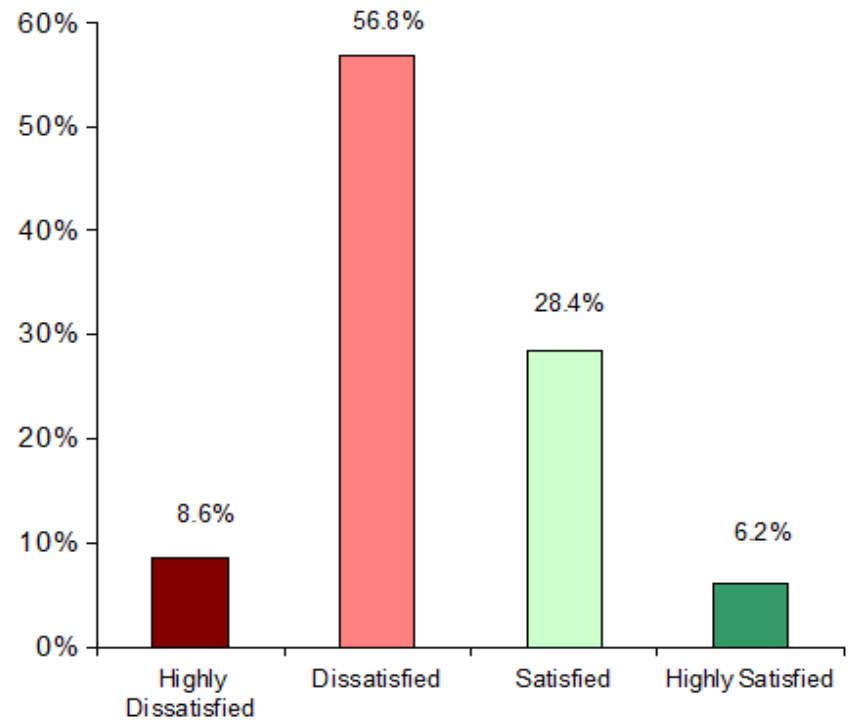

Fig (3) Distribution of the levels of job satisfaction among the community physicians, Sudan ministries of health, Sudan. $(\mathrm{n}=81)$.

\section{Discussion}

The current study showed that there is no significant statistical association between marital status and job satisfaction. In contrary, a similar study conducted in Egypt (6) showed that married physicians are significantly satisfied with their jobs. It also showed that age was not significantly associated with job satisfaction. This was found to be in line with a similar study conducted in Egypt (6) which also reflects that age was not significantly associated with job satisfaction. Unlike these two previous studies a longitudinal study conducted in Norway showed that job satisfaction increases with increasing age (7). This study showed that there is significant statistical relationship between gender and job satisfaction, as females are highly significantly dissatisfied with their work (Table3). In comparison to that a similar survey conducted in Saudi Arabia (8) showed that there is no statistical significant difference in job satisfaction between males and females doctors.Regarding the promotion opportunities this study showed a significant statistical association between having the opportunity to do subspecialty and job satisfaction(Table6). As well as that it reflects a highly significant statistical association between the availability of continuous education and job satisfaction (Table7). 
A similar study conducted in Egypt (6) agreed with these results as it showed a significant association between opportunities for promotion and job satisfaction. These results agreed with the results of a similar study conducted in Pakistan (9) showing that $92 \%$ of the doctors are not satisfied with their career prospects, and $78 \%$ of them would like to leave their jobs and go to serve abroad (Fig1).One of the most dissatisfying factors was found to be the low salaries and incentives, as it is highly significantly associated with job satisfaction(table8). This also agreed with the results of a study conducted in Egypt (6) showing that the vast majority of doctors are not satisfied with their salaries and incentives as only $2.9 \%$ of them are satisfied with their income. Beside that a study conducted in Pakistan (9) showed that there is strong correlation between income and job satisfaction. It was found that $71.6 \%$ of the Sudanese community physicians have the tendency to leave their current governmental jobs (Fig1).

Only $34.6 \%$ of the Sudanese community physicians had expressed overall satisfaction with their jobs (Fig 2). In this regard, similar studies were conducted in Pakistan (9) and another one in Egypt (6) showed that the overall satisfaction was found to be $35 \%$ and $38.7 \%$ respectively. These results are consistent with the finding of this study. Similarly, a study conducted in USA indicates that $59 \%$ of the family physicians were satisfied with their jobs (10). Moreover; the present study had demonstrated that only $6.2 \%$ of the Sudanese community physicians were highly satisfied with their jobs (Fig3). A similar study was conducted in Pakistan (9) and it showed that only $10 \%$ of the doctors are highly satisfied with their jobs, which is slightly more than what was found in this study. In contrary, a longitudinal study conducted in Norway (11) showed that $51 \%$ of doctors are found to be highly satisfied with their jobs, and in particular the public health specialists are showing steady increase in their job satisfaction.

\section{Conclusion}

The current study concluded that $65.4 \%$ of the Sudanese community physicians are not satisfied by their jobs. In particularly, they are found not to be satisfied with their income, the unavailability of chances for training and professional development. The vast majority of the Sudanese community physicians $(71.6 \%)$ have the intention to quit due to wide spread job dissatisfaction.

\section{Acknowledgement}

I wish to thank all Sudanese community physicians who corporate and gave wonderful feed back and made this study interesting. I would also like to thank all those people who helped me directly or indirectly to complete my research work.

\section{References}

[1]. Job satisfaction: cross-cultural diversity: p1-16. Module111 MANAGING MULTI-CULTURAL WORKFORCE, Available at:http://home.skif.net./ todorov/o321.htm on18April2007.

[2]. job satisfaction. Encyclopedia of business and finance, March 2008.p1-4. Available at: http//www.enotes.com/business-financeencyclopedia/job satisfaction/print on 3 March 2008

[3]. Sudan House Hold Health Survey (SHHS), 2006, FMOH, WHO, USAID, UNFPA, UNICEF.

[4]. FMOH. The 10 years' strategic plan for HRH (2004-2013), Khartoum, Solo Press, 2005.

[5]. Sudan Medical Council (March 2008). Administrative records

[6]. Low Job Satisfaction Among physicians in Egypt, 2008. Available at: http://www.korhek.org/khb_007_02-91.pdf

[7]. Magne N, Pal G.Unhappy doctors? A longitudinal study of life and job satisfaction among Norwegian doctors (1994-2002), 2005. Available at:http://bmc.ub.uni.-potsdam.de/1472-6963-5-44/text.htm on30 April 2008.

[8]. Khalid A, Ahmed A. Factors influencing job satisfaction among primary health care (PHC) physicians in Riyadh, Saudi Arabia, 1999. Available at: http://www.kfshrc.edu.sa/annals/195/98-233.PDF.

[9]. Syed S, Ijaz A, Syed A, M.H.Tahir. Job satisfaction Among Doctors working at teaching Hospital of Bahawalpur, Pakistan, 2005. Available at:http:/www.ayubmed.edu.pk/JAMC/

[10]. Shearer S, Toedt M. Family physicians ${ }^{6}$ observations of their practice, well being, and health Care in the United States, 2001. Available at:Http://www.ncbi.nlm.nih.gov/pubmed/11674906 cited on30 April 2008.

[11]. Unni K, Dag H, Marijke V, Per H.Predictors of job satisfaction among doctors, nurses and auxiliaries in Norwegian hospitals: relevance for micro unit culture, 17Feb2006. Available at: http://wwwhuman-resourses-health.com/content/4/1/3\#B28 